\title{
Lawyer Specialisation - Managing the Professional Paradox
}

\author{
by
}

Richard Moorhead

ISBN 978-0-9558097-1-2 


\title{
Lawyer Specialisation - Managing the Professional Paradox
}

Richard Moorhead, Professor of Law, Cardiff Law School, Cardiff University ${ }^{1}$

\begin{abstract}
Specialisation within professions poses some interesting questions that go to the heart of the professional project. Does specialisation undermine the value, rationale even, of the general professional qualification? Or is it a vehicle for intra-professional closure, a means of strengthening the competitive hand of the 'elite'? From the consumer perspective, is specialisation an unalloyed good? Is the way in which the legal professions manage specialisation consistent with them protecting the public or the professions' interests? Utilising empirical data for a series of projects on legal aid programmes in the UK, this paper will examine the tensions between quality and access inherent in the notion of specialisation and consider some of the implications for professional theory and regulation. It will be argued that specialisation, which is a necessary trade-off between consumer interest and detriment, has been resolved by the profession in its own rather than the public's interest.
\end{abstract}

\footnotetext{
${ }^{1}$ I am extremely grateful for comments on an earlier draft from Soren Holm, Bob Lee and Annette Morris. All errors are my own.
} 


\section{Lawyer Specialisation - Managing the Professional Paradox}

\section{Introduction}

Specialisation within professions poses some interesting questions. Do the claims that you need to specialise to be competent undermine the value of, even rationale for, the general professional qualification? Is specialisation a vehicle for intra-professional closure, a means of strengthening the competitive hand of an elite within an elite? From the consumer perspective, does specialisation offer real improvements in quality? Are such improvements an unalloyed good? This paper explores the dependent, yet paradoxically antagonistic, concepts of specialisation and professionalism that these questions raise.

Specialisation is necessary to professionalism: professions are, after all, usually founded on a claim to exclusive application of specialist knowledge. Superficially, all professionals are specialists: lawyers 'specialise' in law, whilst in England and Wales the proliferation of accreditation schemes within the solicitors' profession attests to the increased importance of the distinction between specialists and generalists (SRA 2007). Whilst specialists may (claim to) be the ones leading a field, developing the law and its techniques, and thus advancing the broad claims of the profession to advance the production of specialist knowledge in their client's interests, specialisation also threatens the professional project as intra-professional competition and specialisation intensifies. It does this in two ways. One threat, not the principal focus of this article, is a concern about social, political and cultural homogeneity: the risk that specialisation has, or will, render the professions sociologically fragmented, stratified and lacking in any professional coherence. Whilst principally of political significance, the fragmentation and stratification theses also link to concerns about professional ethics and regulation more broadly. As we shall see, fragmentation also appears to impact on the profession's approach to the second threat.

This second threat is more fundamental: it pertains directly to the profession's core claim to competence. The legal profession typically provides practitioners with a general warrant of competence; on the whole, once qualified a lawyer can practice in 
any area of law. ${ }^{2}$ The existence of specialists raises questions about the validity of this generalist qualification: calling into question whether lawyers are genuinely omni-competent. ${ }^{3}$ Being a specialist necessarily involves a claim to higher quality than being non-specialist. If that claim is well founded, differences in quality expose generalists, and the profession as a whole, to a challenge to their competence. If the professional competence of specialists is significantly higher than that of generalists, and/or if generalists show significant levels of incompetence, then the value of this general warrant of competence is called into question, along with the value of the profession itself.

This paper is able to looks empirically at this issue. It considers the levels of competence demonstrated by specialists and non-specialists in legal aid work in England and Wales. It shows whether such specialists genuinely provide higher quality than non-specialists (referred to below as relative quality) and also whether generalists might nevertheless be 'good enough' (i.e. whether levels of incompetence are at tolerable levels: referred to below as absolute quality). ${ }^{4}$ However, quality is not the only basis on which specialisation should be judged as specialisation comes at a cost. In particular, specialisation has the potential to reduce access and increase cost. Whilst a limited number of studies have addressed the importance of specialisation in the legal profession (Kritzer 1998, Genn and Genn 1989, Moorhead et al, 2003), the empirical work here aims to represent an advance in two senses:

1. it more directly quantifies the differences between specialists and generalists in terms of quality, providing quantitative indicators of relative and absolute quality; and,

\footnotetext{
${ }^{2}$ There are some exceptions to this, for instance, immigration law.

${ }^{3}$ This phrase derives from Heinz and Laumman’s work specialisation in the 1970s.

${ }^{4}$ It is possible to further refine the position. Generalists might be competent enough for certain tasks whilst others may demand specialist knowledge and skills. To keep the paper within manageable bounds this distinction is not pursued in the analysis.
} 
2. it begins to quantify the consumer detriment associated with specialisation enabling an explicit articulation of the tensions between benefit and detriment inherent in professional closure generally and specialisation in particular.

The latter point is important as, to date, professional regulators have indicated a wariness of formalising a recognition of specialisation. Keen not to grant specialists within their ranks competitive advantages over their generalist colleagues, they argue that formalising specialisation reduces the number of suppliers of legal services, makes them harder to access and, in a free market, more expensive. ${ }^{5}$ By bringing both quality and detriment together we can see clearly how the structurally functional benefits of specialisation are necessarily linked with the consumer detriments associated with market control. It follows that specialisation is a microcosm of the dilemma posed more generally by professional services: are the benefits of professional services real and how far are they outweighed by anti-competitive detriments? More specifically, professional regulation of specialisation raises questions of how best to balance quality and detriment and how to best coordinate specialist and generalist practitioners to maximise the interests of consumers.

Where they permit accreditation schemes at all, the profession's current approach to specialisation, to generalise somewhat, is to make accreditation voluntary (so that non-accredited practitioners are not prevented from doing the work) and those accreditation schemes are based on minimal standards of competence (so that all practitioners who wish to gain accreditation stand a reasonable chance of doing so). This is in direct contrast to the legal aid scheme where specialist accreditation is mandatory to be able to carry out significant volumes of legal aid work in the particular specialism. Arguably at least legal aid specialisation is also set at a higher standard.

Having clear data on both the benefits and detriments of compulsion enables us to go some way in evaluating the best approach to regulating specialisation. It will be argued that the profession's approach is incoherent in public interest terms and can be

\footnotetext{
${ }^{5}$ This study does not focus on price increases as it deals with legal aid where there is a monopsonic purchaser (the Legal Services Commission) who controls price; hence detriment is shown by the impact of specialisation on accessibility of provision.
} 
best explained as part of the profession's desire to protect its member's interests and its collective identity. As such it is an example of how the professional paradox, which is a necessary trade-off between consumer interest and detriment, has been resolved by the profession in its own rather than the public's interest.

Before doing so, the paper sets contextualises the discussion by reviewing some of the literature on specialisation (Section II). Much of this literature focuses on specialisation amongst the big firms; this paper concentrates on a different sector of the profession. Section III makes up the bulk of the paper, discussing data from three studies examining the impact of specialistion on quality and accessibility of legal aid services in England and Wales. Section IV discusses the implications of these findings.

\section{Specialisation and the professions: some context and theory}

In the context of professions, the literature on theories of specialisation tend to raise three particularly interesting questions. The first is the supply-demand question. Is specialisation a symptom of external, client-driven demand or does specialisation operate to drive, define, or even manufacture, that demand? In other words: are specialist services supply or demand led? The second is the quality question. To what extent is specialisation associated with improvement in quality? Even if specialist services are 'better' is it possible that they are also narrower and less comprehensive? Specialists may diagnose problems so that that they fit their specialist expertise rather than fit with the client's broader needs for a solution. Relatedly quality may come at a price if specialisation gives rise to other consumer detriment (such as high cost or access problems associated with significant limits on the number of specialists available nationwide). Similarly, some argue that specialisation may narrow the ethical base of specialists. Thirdly, the legitimacy question: does specialisation threaten the legitimacy of the profession's general claim

to competence? Does it lead to intolerable fragmentation within the profession and also reinforce traditional notions of social control in elites where, arguably, they matter most? 


\section{The supply-demand question}

Specialisation within the legal profession is a phenomenon which is both well established (Kahn and Kahn, op.cit., point out it dates back to at least the 1950s) and growing in impact (Heinz et al 2005: 37). Economists point to specialisation as a crucial engine of economic growth: “[B]ecause [specialists] can utilize a particular set of knowledge more intensively when demand is higher” (Garicano and Hubbard 2003: 499; see also Garicano and Hubbard 2004). Efficiency drives growth and law firms’ needs for larger markets promotes greater specialisation.

Sociologists have tended to concentrate on the distributional implications of such an expansion, with elite players using specialisation to reinforce their established success. As markets for legal services expand, those well placed in the markets can solidify their position by expanding and specialising to underline their reputation through that process of specialisation (Heinz et al 2001: 345 in Seron 2007: 583). The causal link between growth and specialisation, and what lies beneath it, is important. If specialisation leads to growth, is this driven by client needs for better, more efficient services, or is specialisation a process through which the profession manufactures the new, more detailed and more expensive services which drive its expansion? In other words, is specialisation a process of mystification which delivers significant benefits to the profession at the expense of consumers or is specialisation a response to larger commercial forces which need and benefit from ever more expensive and extensive legal services?

The growth in the size of the professions and the market for legal services, particularly in the commercial sector, has been phenomenal both domestically and internationally. In terms of firm size, one debate has been whether this growth has been driven by the internal demands of firms to retain and promote staff or by the external needs of the market (Galanter 1990, Sander 1992). Hadfield points to the underlying rationales and structures of common law and the economics of legal work as inappropriately driving increased complexity and cost (Hadfield 2000) whereas others would focus on the capacity to add real value to commercial transactions (Gilson 1984, Gilson 1993). At the heart of these debates is the perennial concern over whether the profession is controlled by, or controls, the market; and whether 
specialisation is developed to aid the internal logic of professional growth or the real needs of clients.

Whilst much of this case for specialisation is economic, the creation of competitive advantage and the desire to promote productivity is also implicated as a device for social control within firms (Heinz et al 2005: 292). Specialties shift and multiply as increasingly bureaucratic and business driven organisations seek to control work in a way which was the sole domain previously of charismatic, client partners (ibid. 303). This horizontal specialisation (splitting law-firms and legal careers into subdisciplines) is accompanied by vertical (or 'hierarchical') specialisation : where senior 'experts’ are shielded from easy problems by the junior colleagues they train and manage, “allowing them to specialize in problems they have a comparative advantage in addressing” as well as using their position, in larger firms, to monitor those below them and coordinate the hierarchies with incentives allowing those at the top of the hierarchy to exploit or maximise the human capital of those below them (Garicano and Hubbard 2004: 2 and 7). ${ }^{6}$

\section{Specialisation and quality}

The economic justifications for horizontal specialisation only implicitly focus on consumer interests: narrower training and practice mean it should cheaper and easier to provide better services. The opportunities provided by growth increase profitability and/or competitiveness but they do not necessarily lead to improvements in quality. Reductions in cost are not necessarily passed on to clients. There are legitimate doubts about the extent to which lawyers genuinely compete for clients on price and the real potential, given the difficulties consumers have in evaluating quality, that high price will be seen as prestigious indication of quality - particularly at the higher ends of the professional market (Hadfield 2000). In the absence of price-competition,

\footnotetext{
${ }^{6}$ Where vertical specialisation involves non-lawyers it brings with it a particular threat to the legitimacy of professions R Moorhead, A. Sherr and A. Paterson, 'Contesting Professionalism: Legal Aid and Nonlawyers in England and Wales, (2003)'37 Law \& Society Review 765-808 ; Feinburg 1994: 371; Kritzer 1999: 720), but these concerns are beyond the scope of this paper which focuses on horizontal specialisation.
} 
professions may exploit comparative advantage and benefits of economies of scale and scope for themselves rather than those they serve.

Similarly, it is easy to see how, given the information asymmetries between professions and their clients, specialisation might be perceived as professional mystification where the specialists develop complex solutions to (legal) problems which only they can validate as right or wrong whether or not simpler solutions would be adequate or even more efficient. On this view, specialisation is a repeat of the fundamental self-referential 'trick' of professionalisation: knowledge developed for, and validated by, the profession's own interests not those of the consumer (Abel 1997) or as a manifestation of law's dysfunctional tendency towards complexity (Hadfield 2000). Conversely, Freidson, for example, defends the impact of specialisation on quality:

"Thus, in the broadest sense, the ideology of professionalism claims that its specialization is fitted to individual tasks rather than standardized production. It claims that the work of a trained and experienced specialist is superior to that of an amateur; in a narrower sense, it claims that the work of a specialist with professionally controlled training is both superior to and more reliable than that of someone who may have experience but lacks training.” (Friedson 2001: 111).

On this reading, specialisation enhances the professions "capacity to be flexible and adaptive in dealing with qualitative differences among individual tasks" (ibid 111112). Educational psychology has classically claimed that specialists see problems differently from the less expert (Schõn 1983) and it is easy to appreciate how specialisation might thus lead to higher levels of quality. Difficult problems become familiar and easy. Specialists become more discerning in their problem-solving strategies. Indeed, a limited number of studies have been able to point in general terms to specialists doing their job better than non specialists in the legal field (Kritzer 1998, Genn and Genn 1989, Moorhead et al, 2003).

\section{Routinisation, subordination, de-ethicalisation}

The claim that specialisation is the preference of professionals, because it enables them to concentrate on work which is then both more rewarding and efficient, is directly challenged by the deprofessionalisation thesis. Under this thesis, specialisation is seen as socially harmful to those who practice it because of an 
association between specialisation, routinisation and the squeezing out of creativity and professional skill (Stefancic and Delgado 2005:10). Lawyer's, often operating under tight economic constraints, respond by routinising: automatically and unreflexively responding to the needs of clients as they are deskilled because law firms become increasingly like factories (Sommerlad 1991 and 2001, Sommerlad and Wall 1995).

Specialisation also has the potential to be detrimental to the 'ethical sense' of the profession. It is claimed that specialisation has advanced alongside a decline in lawyer autonomy (Heinz et al 2005: 12 citing Nelson 1988; Kronoman 1993). In this context, the distributional impact, or unevenness, of specialisation is important: commercial lawyers are bigger, more specialised, wealthier and have higher status they are seen as dominating professional judgments on what is honoured by practitioners:
"While there are competing ideological tropes of prestige, the overall findings suggest a consensus that "service for powerful clients who provide opportunities for both the exercise of arcane skills and a substantial income" trumps fiduciary responsibilities to service the public.” (Seron 2007: 589 citing Heinz et al 2005: 97).

Here, then, the concern is that technical opportunities granted by being able to truly render oneself 'expert' through specialisation, coupled with the significant economic gains accompanying commercial practice where vertical and hierarchical specialisation seems most acute, pose a direct challenge to the public interest values of professionalism. As Heinz and Laumann provocatively demonstrate: the core values of lawyers are not justice oriented, but economic (1977). Law, and specialistion within law, is predominantly a tool for business success. The concern is that lawyers will, through specialisation and other business practices, ape their business clients so wholly as to diminish traditional, collegiate professional paradigms (Seron 2007: 591). This is a familiar refrain in the legal ethics’ literature (e.g. Gordon 2000, Kronman 1993) but, as Seron reminds us, has also been a current in sociological writings on law firms dating back at least to the 1950s (Seron 2007: 590 discussing C. Wright Mills 1953). The idea that business has taken over law has more historical longevity than is often implied; but the concern remains that specialisation transforms the client relationship from a situation where a lawyer-client relationship 
"tended to be personal, general, continuous, and face-to-face... ....is transformed into a more technical, focused, impersonal, case-by-case business-like model.” (Seron 2007: 595).

Interestingly, it can also be argued that de-ethicalisation is achieved by a very different route to that of de-personalistion. The larger, highly specialised commercial law firms tend to emphasise how much they put client interests and business skills at the heart of their approach. This may be attempted as a partial antitode to the perception that specialists milk cases through the development of expensive, overspecialist solutions. Couple this with the desire for specialists to concentrate on particular client groups and they are encouraged to put their creative talents fully in the service of their clients, to become, in Cain's memorable phrase, 'conceptive ideologists' (Cain 1979: 352) rather than seeing their role as operating in the public interest. Under this explanation, specialisation drives de-ethicalisation because it is too personal, lawyers become too close to their clients and fail to think with sufficient levels of forensic detachment.

Both arguments are driven by the apparent dominance of business clients over the profession and its activities but there is a more subtle argument about the way in which specialisation narrows the expertise of lawyers and fails to identify and address the full range of a client's problems; that advice is not suitably holistic in that it fails to address a) latent legal problems outside the specialists expertise and b) fails to address problems in a wider ethical or social context so as to render solutions which are of the most stable and appropriate kind for clients and society (Moorhead et al, 2006). In this sense, specialisation may drive cognitive narrowness, lawyer's seeing problems too narrowly because they only understand a narrow field of law, an issue to which we return below.

\section{Stratification and fragmentation}

Specialisation's impact on the profession at the collective level is also criticised. It is associated with the absence of common beliefs about what is right or wrong in a professional sense (Seron op.cit.: 593) as well as reframing debates about equality and diversity in the profession. Here, the economic efficiency case for specialisation as market closure is paralleled by a process of social closure. Dramatic growth in the size of the profession and broader (if partial) trends towards equality and diversity 
meant women and ethnic minorities had to be absorbed into the profession. Specialisation was a vehicle for permitting this, but in a socially stratified way. The professions may have become more open to women and ethnic minorities, but larger questions remain about the openness of the elites within the professions who retain, up to a point, historic demographic characteristics (Heinz et al 2005; Shiner and Newburn 1995; Heinz and Laumann 1982 in Seron 2007). In this sense, social closure as part of the professional project is moved from the outer boundaries of the profession to its inner elites. Specialisation structures marginalisation and protects elites.

Whilst stratification has enabled the profession to maintain, in its elites, traditional forms of social closure, specialisation itself poses distinct threats to the ideological claim of a common professional bond suggested by a uniform qualification.

Specialist communities within professions may deepen their ties with each other, whilst the profession as a whole has less common-interest and engagement (Heinz et al, 2005: 318-319), prompting fears that professions lack coherence or are "more diverse and less integrated” (Heinz et al 2005: 8). Specialist hierarchies - with their implied technical and meritocratic claims - replace social hierarchies (Heinz et al, 2005: 293), but reinforce the power of elites (elite firms within the profession and powerful partners within the firms). At the political level, specialisation threatens fragmentation.

"Lawyers have taken refuge in specialization, which has made it more difficult for lawyers as a group to identify common economic or ideological interests as a basis for a collective agenda. The growing fragmentation of the bar has been attributed to lawyers' own entrepreneurial ingenuity. As Nelson and Trubek observe, "the key to the economic and political success of American lawyers as a group has been their adaptiveness. But the cost has been the erosion of a distinctive professional tradition and the absence of centralized power within the profession capable of enforcing a particular vision of professional ideals”." (Rostain: 2004: 150 also citing Abel, 1989; Heinz and Laumann, 1982; Heinz et al., 1998)

\section{The paradox of specialisation and professionalism}

Within the context of the debates sketched out above, it is possible to see how the concerns that have been expressed about professionalism are now repeated for, or have shifted to be considered within, debates about specialisation. Of particular interest is the paradox that specialisation presents to professionals. The paradox is 
essentially this: a profession's fundamental claim is to specialised expertise over a body of knowledge (law in this case) which give them exclusive rights to practice that knowledge. Similarly, under this claim, professions which promote specialisation, promote the evolution of knowledge in a way that is theoretically inclined to the better development of that knowledge. Conversely, however, whilst specialisation may advance knowledge, it also threatens to disrupt the profession's internal logic. As specialisation leads to internal differentiation within professions, so it threatens the original rationale or guarantee provided by ‘ordinary’ professional status. Implicitly or explicitly, specialists within professions challenge the competence of less specialised colleagues: it is "increasingly difficult to be a successful non-specialist" when there are successful specialists to compete against (Law and Kim 2005: 729).

These competing stories of specialisation suggest two familiar theoretical strains in the sociology of professions. One is the structural functional vision: professions represent the best available means of managing the provision of complex services. The other is market control theory. The idea that profession's employ their monopoly of expertise to reduce competition to the detriment of consumers. Potentially, specialisation fits both stories. It may improve quality and produce more and better knowledge with which to solve people's problems. Conversely, it may be a mechanism for increasing or solidifying market control by the professions, or elites within them, reducing access and increasing price. Importantly, the theories are basically antithetical. They cannot both be true at the same time. Part of the reason for the resilience of these two theories is that, "the absence of reliable data on the quality of professional services makes it extremely difficult to cleanly distinguish between these two hypotheses.... Whereas the asymmetric information [or functionality] hypothesis argues that licensing should increase quality, the capture [or control] hypothesis argues that quality should remain unchanged, or may even deteriorate as competition is reduced.” (Law and Kim 2005: 725). Another reason for this resilience is that, because evidence and argument on the professions can, relatively easily, be assembled to meet either story both can appear to be true at the same time. As we shall see at the end of this paper, it is the ways in which specialisation are formalised and used by the profession's that gives us an indication of whether professional calculations have appropriately balanced professional selfinterest with public interest. 
The next section of the paper addresses these issues through empirical data on the impact of specialisation on quality and accessibility of legal services. Quality is the principal benefit claimed to arise from specialisation: through looking at this we can get a sense of how structurally functional specialisation really is. It does so through the examination of original empirical data on the quality and accessibility of legal aid services in England and Wales which have moved considerably towards high levels of compulsory specialisation.

The extent to which specialisation advances market control is more difficult to deal with. The obvious problem, that specialists would increase prices, is not a suitable variable in the legal aid arena where prices are largely controlled centrally by a monopsonic purchaser (the State). Other examples of consumer detriment have to provide a focus. In this sense, reduced accessibility is seen as indicating the tendency for specialisation to engender 'control', although consumer detriment is the more accurate phrase. In showing both benefit and detriment, function and control, to be necessarily associated the concept of specialisation the paper seeks to illustrate how the oppositional interpretations of professional monopolies ('detriment' and 'functionality') attributed to professional monopolies can both be present at the same time. This paradox is the paradox that professionalism and specialisation creates and provides the tension that professional regulators have to manage

\section{III: Testing the control versus quality theses}

Developments in the administration of legal aid in England and Wales have provided an interesting opportunity to test the efficacy and implications of specialisation. In the 1990s, the Legal Services Commission (LSC), the governmental, nondepartmental body that administers legal aid, began to move towards encouraging, and, from 2000, requiring specialisation, in the provision of legal aid services. From that point, all providers of legal aid had to have Specialist Quality Marks (SQMs) under the legal aid scheme. This meant that they were quality assured by the LSC in the general sense (i.e. they had met all their management system standards) and also met specialist quality standards in at least one type of law which they were then designated as being specialists in. The most important requirement of the SQM is that the provider has at least one person supervising work in that specialism who is 
themselves specialist in that particular area. ${ }^{7}$ So, for example, if they had an SQM in Housing Law, they would have to have at least one person who specialised in Housing Law and supervised the work of any others doing legally aided housing law in the organisation.

The requirement for supervisors to demonstrate relevant and recent experience in each work category that they supervise was a step change in the Commission's approach. It moved away from a system which relied on firms to self-regulate the experience of their fee earners, and it also meant that, in practical terms, supervisors were limited in the number of work categories that they could supervise. ${ }^{8}$ In effect, firms were required to specialise in areas where they had at least one member of staff with enough experience to meet the supervisor requirements.

In this article, the fact that work is supervised by a specialist is used as a proxy for that advice having been given by a specialist. It is possible for the caseworkers (as opposed to the supervisors), in practice, to be non-specialists but in broad terms caseworkers usually specialise in the one or two particular areas of social welfare law within which they practice. For the purposes of analysis, the group identified below as specialists is likely to be more specialist than those identified as non-specialists; and the differences are sufficiently strong to provide a valuable means of distinguishing the pros- and cons- of specialisation.

Because the LSC recognised that there were access implications from requiring specialists to do all the legal aid work (see below) and the desirability of allowing

\footnotetext{
${ }^{7}$ The supervisor requirements differ depending on which work category is under consideration, but in broad terms supervisors are required to either a) maintain a current caseload in each of the work categories that they supervise, or b) demonstrate their experience in that work category by reference to direct supervision and involvement in cases in the 12 months prior to their being audited. Law Society Panel membership (e.g. in family and clinical negligence) or membership of certain duty schemes (e.g. in crime), is sufficient to demonstrate such experience in some work categories. Another route to meeting the supervisor requirements involves the supervisor certifying that they carried out 350 hours of casework in each of the previous 3 years (roughly assumed to be a third of a normal full-time caseload). Other work categories - e.g. housing, employment, debt, immigration and welfare benefits require demonstrable experience in a range of LSC-specified case types and skills (e.g. representation). There are other requirements for supervisors to be accessible, to keep themselves and their staff up to date, to undergo regular training in each work category, and to subscribe to or have access to certain key texts and journals.

${ }^{8}$ The number of categories they can do is not prescribed, but de facto supervisors would struggle to meet supervisor requirements and keep current experience in more than two or three work categories.
} 
providers to develop new specialties, legal aid providers were not required to confine themselves purely to the work they specialised in (Legal Services Commission 2002). Hence, they were permitted, under what were called 'tolerances', to do a limited amount of work outside their recognised speciality (the figures vary, but they were generally permitted to do about $10 \%$ of their work outside of their recognised specialties). This non-specialist work provides us with a comparison with specialist work.

\section{The Studies}

This paper reports on three studies conducted for government agencies on the workings of the England and Wales legal aid scheme: ${ }^{9}$

- The Anatomy of Access Study (which establishes the level of advice provided by 'generalists’through the use of model clients, (Moorhead and Sherr 2003);

- Quality and Access? (Moorhead and Harding 2004) which provides a direct comparison of the quality of non-specialist and specialist casework through a comparison of case outcomes, peer review by specialist solicitors, and a comparison of management, training and supervision of non-specialist and specialist work;

- The Clusters Study (Moorhead et al 2006) which looks in particular at how non-specialists and specialists deal with multiple problems (clusters of problems) and enables some consideration of the extent to which nonspecialists and specialists deal differently with linked and latent problems to the one's a client presents with.

To keep this paper within manageable length, only an abbreviated discussion of methods is contained below in each relevant section.

\footnotetext{
${ }^{9}$ The studies were conducted with a number of collaborators who's contributions are gratefully ackolwedged: Professors Avrom Sherr and Alan Paterson, Drs Richard Harding and Margaret Robinson, Matrix Research and Consultancy and Thornton Drummond and Brett.
} 


\section{Anatomy of Access: The quality of 'quality assured' non-specialists}

The Anatomy of Access Study provides a direct assessment of the quality of advice given by specialist solicitors and advice workers when operating outside their specialism. The LSC had, as part of their Quality Mark, a requirement that, where a matter fell outside a provider's expertise, the client should be referred or signposted onto a specialist provider. Anatomy of Access was principally designed to assess this. Specialist providers were approached by a researcher posing covertly as a client (a 'model client') with a problem outside their specialism(s) and the model client could then report on how they were dealt with. 294 Specialist Quality Mark holders were approached in this way.

The model clients were trained researchers sent to solicitors and advice agencies to pretend they are clients and seek advice. Pioneered in Quality and Cost (Moorhead et al 2001) concerns about consent and invasion of privacy mean such techniques must be employed with great care. ${ }^{10}$ Model clients do, however, present major advantages over other methods. ${ }^{11}$ The model client scenarios (their cases, or alternatively, the stories that they told) were based on stories taken form real legal aid files and designed in such a way as to suggest to a competent non-specialist adviser that the client had reasonably pressing needs which required specialist attention in an area that the lawyer/adviser did not hold a specialist contract. Debt, housing and education were the three areas of work selected. Each model client visited or telephoned an organisation without a specialist contract in the work category that their problem fell into. The specific aim of the research was to test whether, and how effectively, non-

\footnotetext{
${ }^{10}$ The approach we adopted complies with the Socio-Legal Studies Association's guidelines on covert research. Solicitors' firms and advice agencies consented to model client visits as part of their contract with the Legal Services Commission and publicity for the project was sent to each and every account holder. Anonymity was guaranteed: no data from any model client interview was used to identify an individual or their organisation to the Legal Services Commission (or anyone outside the research team) in any way. Thus, whilst providers were aware of, and had consented to, model client visits occurring at some time during the life of their contract, they were not advised in advance of when visits were imminent. We had no evidence of model client's being identified during the course of their visit. See, SLSA (2002), Socio-Legal Studies Directory 2002, (Butterworths, London) and Anatomy of Access, pp. 9-10

${ }^{11}$ Other methods of research lawyer on quality have tended to rely on the reviewing lawyer's files (which contain important but limited information on lawyer quality) and/or observation of lawyers in practice settings when they lawyers would have been aware of the lawyer's presence and able to modify their behaviour accordingly.
} 
specialists signposted (referred) clients onto more appropriate providers and, where they provided advice, to test the quality of that advice. That testing was done by asking model clients to record the advice they had been given immediately after their visit and then asking specialist solicitors' to evaluate the quality of that advice. Whilst advice only occurred in a minority of cases, it is the advice which is of major interest to us as it is that which indicates the quality of non-specialists.

\section{Anatomy of Access Results}

Of the visits attempted, $12 \%$ resulted in severe access problems (model clients could not get through on the phone, or were simply turned away by the suppliers they visited). Between $35 \%$ and $40 \%$ of clients were signposted to an appropriate supplier and between $35 \%$ to $40 \%$ were signposted to a less appropriate provider (i.e. they were not signposted to a local specialist when it appeared they could have been). In the remaining $18 \%$ of cases, these clients were advised by the providers they approached and not signposted on. Whilst this is a minority of the visits arranged, it is worth emphasising that those giving the advice were under no obligation to advise and had decided for themselves that they were sufficiently competent to provide the advice. Furthermore, the problems identified in the advice sit alongside the more general problems of severe access problems and poor signposting to give a general indication of how well those operating in the legal aid scheme work when dealing with non-specialist problems. The results are startling.

Peer reviewers were asked five particular questions about the quality of advice given to model clients, and these are reported in Table 1. The key findings are:

- only $20 \%$ of the advisers/lawyers who provided advice to our model clients were very aware or quite aware of all the legal issues raised;

- $70 \%$ were inadequately or completely unaware of the legal issues raised. Marginally fewer advisers were very or quite aware of the practical steps that could be taken (16\%); and,

- $72 \%$ were inadequately aware or completely unaware.

The figures were similar for comprehensiveness and accuracy of advice given. 
How aware is the adviser of all legal issues raised?

Very aware

Quite aware

Adequately aware

How aware is the adviser of practical steps that can be taken now or in the future?

Very aware

Quite aware

Adequately aware

How would you assess the comprehensiveness and accuracy of advice on this case?

Very good

Good

Adequate

Inadequate

52.0

Poor

How would you assess the plan of action given to the client?

Very useful

Useful

Neither useful nor counterproductive

Counterproductive

Damaging to the interests of the client

In your view how justified was the adviser's decision to advise rather than refer/signpost?

Justified

Probably justified

Don't know/unsure

4.0

Probably not justified

Not justified

40.0

In this context, we were further concerned to know the extent to which poor advice would be likely have a detrimental impact on real clients. To this end peer reviewers were asked to assess the plan of action given to the model client. $16 \%$ of model 
clients received a plan of action which was neither useful nor counterproductive, $8 \%$ of plans were counterproductive and a notable $40 \%$ were, in the view of our expert peers, likely to be damaging to the interests of the client. This is telling evidence of the level and seriousness of the poor quality of advice given to our model clients. Peer reviewers were also asked to indicate how justified was the adviser's decision to advise rather than refer/signpost. In $66 \%$ of cases the peer reviewers felt the decision was not, or probably was not, justified.

As well as scoring the advice given to the model client, more detailed reports from the peer reviewers also suggested what was wrong with the advice. Aspects of the advice were either wrong or missing and advisers tended to rely on weak strategies such as suggesting the client negotiated with potential adversaries unaided by concrete advice. Non-specialists were seen to skate around the area of law in question without giving any firm advice.

Of course it could be argued that the standards applied by peer reviewers (as specialists) were higher than should be expected of non-specialist advice. There is some force in this argument, but peer reviewers tended to give advisers the benefit of the doubt where they provided partial advice, even if it did not help the client, as long as it was not misleading or potentially prejudicial and the client was invited to come back for more advice as their problem developed. If anything, this suggests a generous caution about forming negative judgments on the part of the peer reviewers.

\section{Are specialists any better?}

The Anatomy of Access Study suggests that in absolute terms the quality of advice given out by non-specialists, when they had chosen not to refer clients to specialists, was extremely poor. This raises a significant question mark over any general warrant of competence being provided by a professional qualification (or indeed the general aspects of quality assurance provided by the LSC’s Quality Mark), but it does not establish the value of specialisation. To do that one has to establish that specialists perform better than non-specialists . A second study looked directly at the differences in quality between specialists and non-specialists: Quality and Access? (Moorhead and Harding 2004). 


\section{The Quality and Access Study: Methods}

Five main kinds of data were used in the analysis of quality of specialist and nonspecialist work:

- Billing data a large sample of over 600,000 bills on legal help cases ${ }^{12}$ completed in 2001 had outcome and other data which could be used to provide indicative insights into quality;

- Postal survey data from suppliers carrying out larger volumes of nonspecialist cases about how they managed specialist and non-specialist cases. 156 of the 387 suppliers sent questionnaires responded; a response rate of $40 \%{ }^{10}$ Respondents were broadly representative of those suppliers sent questionnaires.

- 12 semi-structured telephone interviews with a sample of practitioners from those who indicated on the postal questionnaire a willingness to be interviewed; and,

- Peer review of a stratified random sample of 643 files (342 specialist and 301 non-specialist files) took place in late 2002. ${ }^{13}$ Peer reviewers (solicitors with significant experience in the work areas under consideration) marked the quality of work as recorded on those files from attendance notes,

\footnotetext{
${ }^{12}$ In broad term legal help cases are cases which do not proceed to litigation. The range from initial advice and assistance to more sustained negotiation and, more occasionally and in limited circumstances, representation in tribunal type proceedings.

${ }^{10}$ This is a good response rate for postal-questionnaire-based research. Nevertheless, the results must be interpreted carefully. The responses were checked for signs of response bias in terms of the type of contractees responding and their approach to non-specialist work. Contractees with contracts in community care and/or medical negligence were less likely to respond than contractees in other work categories, and so were underrepresented in our sample. Only a small minority of contractees have contracts in community care and/or medical negligence, however.

${ }^{13}$ We selected 951 cases at random from the LSC's list of all matter report forms (MRFs: these were billing forms specifically developed to record key information for the research). in three work categories: debt, housing, and welfare benefits. The samples were stratified to ensure that roughly equal numbers of specialist and non-specialist cases were included in each work category. 643 files were returned by legal aid providers and reviewed by solicitor peer reviewers. Because not all requested files were returned, one concern is that there could be a degree of adverse selection, with firms tending to send their better files and retain the ones they were worried about. Our response bias testing suggested no systematic difference in the rate of return of files.
} 
correspondence and the like, utilising the methodology employed in a previous study Quality and Cost (Moorhead et al, 2001).

\section{Was quality any different for specialists?}

One way of assessing quality of work is to look at the outcomes achieved for clients. The type of work we were looking at means such comparisons are limited. As (usually) small cases of initial advice and assistance cases, they often would not be expected to produce a result for the client. ${ }^{14}$

There are other controversies in using outcome to evaluate the quality of advisers: results depend partly on the qualities of advisers, partly on the quality of cases and partly on the quality of opponents and third parties such as adjudicators and judges (Moorhead et al 1994). In the context of this paper, in particular, it is possible that specialists would get better results because they get better cases, although we sought to control for this as far as we could in our analysis. Nevertheless, outcomes do provide one interesting viewpoint on the quality of work.

Two basic comparisons of outcome were conducted. The first comparison involves looking at whether cases completed. For each of the four work categories considered, the cases of non-specialists were significantly less likely to complete than were specialists' cases: clients of non-specialists were significantly more likely to cease giving instructions, go elsewhere or be told by their adviser the case should not be continued with. In welfare benefits cases, employment and debt these differences were of the order of 6-16\%; in housing the difference was only $2 \%$. The differences were statistically significant.

\footnotetext{
${ }^{14}$ Advice in and of itself may be a sufficient benefit or the benefit may not be directly testable; e.g. a client asking for advice on entitlement to welfare benefits may or may not go on to get those benefits if and when they apply but the adviser would not necessarily know.
} 
Table 2: Comparing the number of cases that completed by specialists and non-specialists

\begin{tabular}{|c|c|c|c|c|c|c|c|c|}
\hline & \multicolumn{2}{|c|}{ Welfare benefits } & \multicolumn{2}{|l|}{ Debt } & \multicolumn{2}{|c|}{ Employment } & \multicolumn{2}{|l|}{ Housing } \\
\hline & Specialist & $\begin{array}{l}\text { Non- } \\
\text { specialist }\end{array}$ & Specialist & $\begin{array}{l}\text { Non- } \\
\text { specialist }\end{array}$ & Specialist & $\begin{array}{l}\text { Non- } \\
\text { specialist }\end{array}$ & Specialist & $\begin{array}{l}\text { Non- } \\
\text { specialist }\end{array}$ \\
\hline $\begin{array}{l}\text { Did not } \\
\text { complete }\end{array}$ & $33.1 \%$ & $49.4 \%$ & $39.0 \%$ & $48.9 \%$ & $55.0 \%$ & $60.8 \%$ & $51.7 \%$ & $53.6 \%$ \\
\hline Completed & $66.9 \%$ & $50.6 \%$ & $61.0 \%$ & $51.1 \%$ & $45.0 \%$ & $39.2 \%$ & $48.3 \%$ & $46.4 \%$ \\
\hline$N$ & $N=56,594$ & $n=6,312$ & $n=25,430$ & $n=11,865$ & $n=4,787$ & $n=3,472$ & $n=53,123$ & $n=13,001$ \\
\hline $\begin{array}{l}\text { Significance } \\
\text { (chi-square) }\end{array}$ & \multicolumn{2}{|c|}{$P<=0.001, X^{2}=663.9$} & \multicolumn{2}{|c|}{$p<=0.001, X^{2}=324.1$} & \multicolumn{2}{|c|}{$p<=0.001, X^{2}=28.3$} & \multicolumn{2}{|c|}{$p<=0.001, X^{2}=15.284$} \\
\hline
\end{tabular}

An analysis of the actual outcomes on cases was also completed. The important differences are identified and highlighted in Table 3.

Table 3: Outcomes by specialist (completed cases) - main differences

\begin{tabular}{|c|c|c|}
\hline Outcome & Contract & Tolerance \\
\hline \multirow{3}{*}{$\begin{array}{l}\text { Client receives lump sum payment } \\
X^{2}=514.7, p<=0.001 \\
\text { Client receives extra or new regular payment } \\
X^{2}=231.7, p<=0.001\end{array}$} & \multicolumn{2}{|c|}{ Welfare benefits } \\
\hline & $\begin{array}{l}14.6 \% \\
(n=8,329) \\
14.3 \% \\
(n=8,126)\end{array}$ & \multirow[t]{2}{*}{$\begin{array}{l}4.3 \% \\
(n=272) \\
7.4 \% \\
(n=464)\end{array}$} \\
\hline & Debt & \\
\hline $\begin{array}{l}\text { Client makes extra or new regular payment } \\
X^{2}=740.0, p<=0.001\end{array}$ & $\begin{array}{l}18.0 \% \\
(n=4,567)\end{array}$ & $\begin{array}{l}7.3 \% \\
(n=865)\end{array}$ \\
\hline \multirow{3}{*}{$\begin{array}{l}\text { Client receives or retains property or other permanent } \\
\text { benefit } \\
X^{2}=345.1, p<=0.001\end{array}$} & Housing & \\
\hline & $\begin{array}{l}10.2 \% \\
(n=5,407)\end{array}$ & $\begin{array}{l}4.9 \% \\
(n=642)\end{array}$ \\
\hline & \multicolumn{2}{|c|}{ Employment } \\
\hline $\begin{array}{l}\text { Client receives lump sum payment } \\
X^{2}=296.3, p<=0.001\end{array}$ & $\begin{array}{l}28.5 \% \\
(n=1,364)\end{array}$ & $\begin{array}{l}12.6 \% \\
(n=439)\end{array}$ \\
\hline
\end{tabular}

About $29 \%$ of specialist welfare benefits clients got lump sump or periodic payments, whereas only $13 \%$ of non-specialist clients did. Put another way, on these figures, welfare benefits clients seeing specialists were more than twice as likely to get a positive financial result as clients being dealt with by non-specialists. Differences were similar in employment, debt and housing. It is possible that variations in positive outcome are explained by the differences in the profiles of specialist and non- 
specialist cases in terms of case types, levels of case, etc. This was tested by performing multiple logistic regressions in welfare benefits and employment cases. The regressions confirmed that, even when differences in case profile, cost of cases and level at which the case completed at are controlled for, the difference in positive outcomes in employment and welfare benefits was statistically significant. Nonspecialist clients were about half as likely to get positive financial results in welfare benefits cases, and about half as likely to get positive results in employment cases as clients being served under specialist contracts. ${ }^{15}$

\section{Do differences in the way non-specialist work is managed suggest quality is likely to be lower?}

From interviews with practitioners, staffing patterns and management of nonspecialist work were considered to explore how management issues might interrelate with quality concerns. In general, the impression given was that practitioners did not adapt their working practices significantly just because work was non-specialist. To take staffing patterns, for example, there was no clear pattern in the level of staff to which non-specialist work was delegated. In particular, counter-intuitively, relatively few (about 15\% of) respondents always delegated non-specialist work to unqualified staff. The picture on supervision was more equivocal. If non-specialist work was low-level work, supervision on 'easy’ cases may not be a particular concern.

Conversely, non-specialist work by definition involved providers in cases where they were less likely to have experience, and so supervision might have needed to be stronger than it was for work which was their mainstay. As our analysis of quality suggests most persuasively below, stronger supervision is preferable where nonspecialist work is seen to be done to worrying standards.

Only a minority (albeit a substantial minority, 37\%) of respondents said they had special supervision arrangements for non-specialist work. One in five respondents actually reviewed fewer non-specialist files than in their main contract categories. Similarly, no relationship was found between the level of fee earner providing advice on non-specialist cases and the way in which files were supervised. So providers

\footnotetext{
${ }^{15}$ See Tables A8 and A9, Appendix A in Quality and Access
} 
using non-qualifieds to do non-specialist work were not compensating by implementing specific supervisions arrangements for this work. One potential barrier to greater supervision was the absence of anyone with significant experience in the relevant area of law to provide that supervision hence comments received in interviews which suggested a very light touch to supervising non-specialist work.

Furthermore, the results did not suggest that the majority of advisers received training specific to each work category in which they conduct non-specialist work. When asked what training they had received in non-specialist areas, respondents tended to emphasise the general training provided to lawyers during the undergraduate and vocational training stages. Given the emphasis of most undergraduate and vocational courses in the UK, which would relatively rarely cover debt, housing and welfare benefits, it is doubtful that such training covers the sorts of work that was covered in this survey.

\section{Peer review of non-specialist and specialist work}

In addition to an analysis of outcomes and management systems, solicitors with experience of the relevant field of law were asked to evaluate the case files of specialists and non-specialists. Table 4 summarises the overall rating given to solicitors. ${ }^{16}$ A score of 1 represents very poor (or non-) performance. A score of 5 indicates very good performance. A mark of 3 indicates satisfactory performance. Hence a score of less than 3 is indicative of quality concerns on a file.

Table 4: Overall mark - 1-5 (solicitors only)

\begin{tabular}{cccc}
\hline Overall score & Specialist & $\begin{array}{c}\text { Non- } \\
\text { specialist }\end{array}$ & $N$ \\
1 & $6.2 \%$ & $6.6 \%$ & 29 \\
2 & $24.1 \%$ & $35.9 \%$ & 142 \\
3 & $42.0 \%$ & $35.5 \%$ & 170 \\
4 & $24.1 \%$ & $19.5 \%$ & 95 \\
5 & $3.7 \%$ & $2.4 \%$ & 13 \\
$n$ & 162 & 287 & 449 \\
\hline
\end{tabular}

\footnotetext{
${ }^{16}$ The study looked at advice given by solicitors firms and non-solicitors. For this paper the results for solicitors firms are concentrated upon.
} 
For solicitors' cases, 30\% of specialist files were marked at 2 or lower and $43 \%$ of non-specialist files were similarly marked. The difference in the distribution of marks is significantly different at the normal levels. ${ }^{17}$ However if the solicitors' results are considered by work category, then the picture is interesting (see Table 5). 46\% of debt cases and $47 \%$ of welfare benefits cases handled by solicitors under non-specialist were scored 2 or less compared with 37\% of debt and 21\% of welfare benefits cases handled by solicitors under contract. However, only the difference for welfare benefits cases was significantly different. ${ }^{18}$ Housing cases had similar rates of 'failing' cases for specialist and non-specialist (35\% specialist compared with 32\% non-specialist).

Table 5: Overall mark - 1-5 (by non-specialist and work category, solicitors only)

\begin{tabular}{ccccccc}
\hline Overall & \multicolumn{2}{c}{ Debt } & \multicolumn{2}{c}{ Housing } & \multicolumn{2}{c}{ Welfare Benefits } \\
Mark & Contract & Tolerance & Contract & Tolerance & Contract & Tolerance \\
1 & $6.7 \%$ & $7.1 \%$ & $8.5 \%$ & $4.9 \%$ & $3.3 \%$ & $7.5 \%$ \\
2 & $30.0 \%$ & $39.3 \%$ & $26.8 \%$ & $26.8 \%$ & $18.0 \%$ & $39.8 \%$ \\
3 & $53.3 \%$ & $39.3 \%$ & $33.8 \%$ & $40.2 \%$ & $45.9 \%$ & $26.9 \%$ \\
4 & $6.7 \%$ & $13.4 \%$ & $25.4 \%$ & $24.4 \%$ & $31.1 \%$ & $22.6 \%$ \\
5 & $3.3 \%$ & $0.9 \%$ & $5.6 \%$ & $3.7 \%$ & $1.6 \%$ & $3.2 \%$ \\
$N$ & 30 & 112 & 71 & 82 & 61 & 93 \\
\hline
\end{tabular}

Analysis of more detailed quality criteria, enables a more comprehensive consideration of differences in competence between non-specialists and specialists. Non-specialists were significantly worse than specialists on:

- $\quad$ fact- and information-gathering skills; ${ }^{19}$

- $\quad$ comprehensiveness of advice; ${ }^{20}$

- advice being given in time/at the right time; ${ }^{21}$ and

\footnotetext{
${ }^{17}$ Mann-Whitney U test, $\mathrm{p}=.021$

${ }^{18}$ Mann-Whitney U tests: Debt, $\mathrm{p}=0.59$; Housing, $\mathrm{p}=.909$; and welfare benefits, $\mathrm{p}=0.014$

${ }^{19}$ Chi-square $9.763, \mathrm{p}=0.045$

${ }^{20}$ Chi-square 12.293, $\mathrm{p}=0.015$
} 
- the effectiveness with which the client was informed of the merits (or not) of the claim. ${ }^{22}$

In other areas, the differences were near (but did not meet) conventional levels of statistical significance: appropriateness of the advice to the client's instructions; ${ }^{23}$ and effectiveness in working towards what the client reasonably wanted/needed through letter-writing and form-filling. ${ }^{24}$ It is also worth noting that the NFP files scored more highly than the solicitors' specialist files on every single criterion, getting higher positive and negative scores on each one. These differences were statistically significant for all criteria bar one. ${ }^{25}$

Peer reviewers also wrote reports which supplemented their scores and provided qualitative information on the quality problems perceived on files. The content of these was analysed and the following problems were identified as being more prevalent on non-specialist files:

- lack of advice on the files, suggesting a situation where lack of expertise prevents an adviser formulating any practical solution or opinion on the case which will help the client;

- lack of basic understanding of the problems and solutions to be offered to a client;

- $\quad$ wrong advice;

- lack of relevant information; and,

- lack of action.

\footnotetext{
${ }^{21}$ Chi-square 13.218, $\mathrm{p}=0.010$

${ }^{22}$ Chi-square 10.737, $\mathrm{p}=0.030$

${ }^{23}$ Chi-square 9.315, $\mathrm{p}=0.054$

${ }^{24}$ Chi-square 8.453, $\mathrm{p}=0.076$

${ }^{25}$ Using chi-square tests, $\mathrm{p}<0.05$ save for the question, if no other work was carried out, was this appropriate? Which was near significant $(p=0.06)$.
} 
The following comments indicate the concerns on the more problematic cases:

"Firm are under an obligation to use their skills to investigate or to tell client the appeal is hopeless. They do neither." (Welfare benefits non-specialist advice)

“...The adviser appears to know absolutely nothing about housing law or court procedures. If he does then there is no evidence of this on the file whatsoever. There is no evidence of the most basic questions being asked as to the client's status as an occupier of the dwelling. Without that then it is difficult to see how the adviser could believe that proper and full advice could be given... The worrying thing about this file is that the file appears to have been reviewed by a 'supervisor' who does not see anything wrong with it" (Housing non-specialist)

"This file is a disgrace and borders on negligence - despite the long-winded attendance notes/letter[s], the adviser does not appear to know what the rules of entitlement are, as many aspects of the fact finding are irrelevant...." (Welfare benefits non-specialist)

"The file displayed a total lack of understanding or indeed any attempt to understand and advise the client.” (Housing non-specialist)

\section{From quality to closure}

The results of Anatomy of Access and Quality and Access suggest reasonably consistently that specialists provide higher levels of quality than non-specialists and that in absolute terms the quality of non-specialist advice can be worryingly poor. This is consistent with the structural functionalist claims of specialisation, whilst also providing telling evidence on the limits of a professional qualification as a general warrant of competence. Where it has been possible to test it, generalists provide quality of advice which are worryingly low. Compulsory specialisation appears to improve quality but this leads us onto the second limb of the debate: does closure also lead to detriment to the consumer and, if so, how extensive is this?

One way in which detriment would be expected to occur is that specialists might exploit their marginal advantage in terms of quality and/or scarcity and drive up their prices. With the LSC controlling prices of legal aid work, there is limited opportunity for this to occur in this context. A related way in which consumer detriment might occur (because the professions cannot put up their prices or because they cannot access sufficiently large markets) is the reduction in access that might arise through scarcity. In Quality and Access the analysis of billing data which was used to consider outcomes (above) also provided indicative data on access. In particular, it 
was possible to show what proportion of the work was carried out both by specialists and by non-specialists and how well dispersed specialist coverage was geographically. Table 6 considers the first issue. ${ }^{26}$

Table 6: How much work in any particular work category is non-specialist work?

\begin{tabular}{lccr}
\hline & Generalists & Specialists & \multicolumn{1}{c}{$N$} \\
\hline Consumer/contract & $84 \%$ & $16 \%$ & 8,068 \\
Actions against the police & $56 \%$ & $44 \%$ & 4,001 \\
Employment & $42 \%$ & $58 \%$ & 8,259 \\
Education & $41 \%$ & $59 \%$ & 2,711 \\
Personal injury & $28 \%$ & $72 \%$ & 8,269 \\
Debt & $32 \%$ & $68 \%$ & 37,301 \\
Community care & $34 \%$ & $66 \%$ & 1,557 \\
Housing & $20 \%$ & $80 \%$ & 66,165 \\
Welfare benefits & $10 \%$ & $90 \%$ & 63,285 \\
Medical negligence & $7 \%$ & $93 \%$ & 3,603 \\
Mental health & $1 \%$ & $99 \%$ & 19,370 \\
\hline
\end{tabular}

For two work categories - consumer, and actions against the police -clients gained access to legal help predominantly from non-specialists indicating major access problems in this type of work. About one (or more) clients in three were gaining legal advice on problems in employment, education, debt and community care under nonspecialist, and one in five housing clients were getting advice under non-specialist. This suggests a substantial need for advice, which was not being met by specialists under the legal aid scheme. Indeed, this may underestimate the size of the problem. Many contractees only did non-specialist work in a limited number of work categories. It is not known whether clients who approached these contractees were successfully referred on to an appropriate supplier of advice, or whether the clients decided to simply 'lump' (put up with) their problem and not seek advice, although the evidence is that this is likely to be a considerable problem. ${ }^{27}$

While, these figures paint a national picture, there were regional variations which suggested that in many parts of the country the picture would be likely to be worse,

\footnotetext{
${ }^{26}$ Public law/civil liberties is excluded because this was the one area where the LSC system failed to identify contractees doing specialist work under contracts.

${ }^{27}$ Anatomy of Access shows considerable problems with the quality of referral and Pleasence at al (2004: 76) shows how referral fatigue means that the likelihood of a client seeking advice declines with each referral.
} 
particularly outside large urban connurbations. At the time of the research, the LSC was using the bid zone as its main unit for measuring the geographic dispersal of supply of legal aid services. In broad terms, bid zones were geographic areas usually coterminous with local authority boundaries. ${ }^{28}$ Bid zones were therefore used in Quality and Access as the unit of analysis in considering the supply of legal help. ${ }^{29}$

As Table 7 shows, within bid zones there was more variation in the supply of services by work category than the national figures suggest. On these data, even in mainstream areas of legal help, a large proportion of bid zones had no specialist contract holder. $42 \%$ of bid zones had no welfare benefits specialist funded by the LSC. The percentages of bid zones without a specialist contractee were: for debt, $40 \%$; housing, 44\%; and employment, 63\%.

Table 7: Proportion of bid zones where there is no specialist contractee in that work category

\begin{tabular}{lr}
\hline Work category & $\mathbf{\%}$ \\
\hline Public law & $95 \%$ \\
Community care & $91 \%$ \\
Actions against the police & $90 \%$ \\
Education & $89 \%$ \\
Consumer contract & $84 \%$ \\
Immigration & $68 \%$ \\
Medical negligence & $63 \%$ \\
Employment & $63 \%$ \\
Mental health & $54 \%$ \\
Housing & $44 \%$ \\
Welfare benefits & $42 \%$ \\
Debt & $40 \%$ \\
Personal injury & $13 \%$ \\
Matrimonial & $0.5 \%$ \\
$N$ & 410 \\
\hline
\end{tabular}

\footnotetext{
${ }^{28}$ London boroughs, unitary authorities or district council boundaries

${ }^{29}$ It should be noted that in terms of planning supply, certain services, especially specialist services such as immigration and mental health, may only be expected to be supplied at a regional level rather than at bid zone level. Similarly, the level of legal need differs from bid zone to bid zone. As a result, supply might be expected to vary from bid zone to bid zone in individual work categories. It might not be expected that even mainstream work categories would be supplied in each bid zone under specialist contracts. Nevertheless, bid zones provided the most convenient and meaningful unit to analyse supply available to the research.
} 
Similarly, certain bid zones had higher levels of tolerance work than others. About one in ten bid zones (9\%) had more than $30 \%$ of legal help matters conducted under tolerance. About one in five bid zones (21\%) had more than a quarter of legal help matters handled under tolerance. These bid zones include urban areas such as Gateshead and parts of Liverpool and Manchester, but were otherwise predominantly rural bid zones.

It should also be noted that the data record the position in 2001. The access problem is underlined when one looks at the trend in supply of legal aid in the years subsequent to the study. Table 8 shows the significant decrease in the number of contracts across the board and within specific subject areas suggesting a further significant diminution in geographic coverage. It is clear that, as specialisation requirements from the Legal Services Commission have taken hold, and as (the profession argues) legal aid has become less (or even un-)profitable, the number of providers willing to specialise in particular areas of legal aid has decreased. As I have argued elsewhere this decline can be attributed partly to economics; partly to the general bureaucracy associated with legal aid provision; and partly to the requirements of specialisation itself (Moorhead 2004). In particular, as firms struggled to find or maintain supervisors with the necessary level of specialisation they abandoned legal aid work either all together or outside of their core business. Whilst concerns with the levels and costs of bureaucracy associated with legal aid contracts were strong and the low profitability of legal aid work was a constant and pressing concern for practitioners, compulsory specialisation was the factor which tipped many firms away from legal aid work. 
Table 8: Civil legal aid contracts ${ }^{30}$

\begin{tabular}{lrrr}
\hline Civil contracts by category & $\mathbf{1 9 9 9 -}$ & $\mathbf{2 0 0 5}-$ & $\begin{array}{r}\text { Cumultaive } \\
\text { change }\end{array}$ \\
Family & $\mathbf{2 0 0 0}$ & $\mathbf{2 0 0 6}$ & $-32 \%$ \\
Housing & 4243 & 2887 & $-30 \%$ \\
Welfare Benefits & 840 & 587 & $-32 \%$ \\
Debt & 673 & 459 & $-35 \%$ \\
Immigration & 618 & 401 & $-24 \%$ \\
Employment & 483 & 367 & $-46 \%$ \\
Mental Health & 403 & 216 & $-15 \%$ \\
Clinical Negligence & 334 & 283 & $9 \%$ \\
Consumer & 250 & 273 & $-79 \%$ \\
Education & 193 & 40 & $57 \%$ \\
Community Care & 35 & 55 & $181 \%$ \\
Public Law & 27 & 76 & $411 \%$ \\
All (excl Personal Injury ${ }^{31}$ ) & 9 & 46 & $-30 \%$ \\
\hline
\end{tabular}

\section{The Clusters Study: Specialisation and the problem of cognitive narrowness}

Concerns about cognitive narrowness derive from a number of sources. One is the not-for-profit (NFP) advice movement's championing of 'holistic' advice. This has emphasised that advice service delivery should respond to the notion that clients' problems are often multi-faceted; legal and non-legal; and complex and interrelated and not simply draw on narrow legal techniques for problem resolution. This claim is founded on the belief that specialist legal training and the economic incentives of private practice, militate against lawyers providing the rounded service that clients need. The importance of holism sits well with recognition that client's legal needs tend to cluster: clients with one legal problem are reasonably likely to have multiple problems (Pleasence et al, 2004a; 2004b and 2006). There is also an increasing amount of evidence of the interrelationships between legal and non-legal problems, especially in health (Moorhead et al, 2004; Sherr et al, 2002).

\footnotetext{
${ }^{30}$ Source: Constitutional Affairs Select Committee (2007) Third Report - Implementation of the Carter Review of Legal Aid HC 223-I (London: Stationery Office), page 15.

${ }^{31}$ Personal Injury cases arising from negligence other than medical negligence were removed from the scheme hence ht figures would have been $100 \%$ for personal injury work.
} 
The Clusters Study examined how clients with multiple problems that crossed specialist boundaries (clusters) were dealt with by both specialist and non-specialist advisers (Moorhead et al, 2006). It looked in-depth at a mixture of twelve providers. ${ }^{32}$ The research utilised a multi-method approach including: structured observation of 178 interviews between advisers and clients; structured interviews with advisers on 487 additional cases; and 35 semi-structured interviews with advisers about clients with multiple problems and surrounding service-delivery issues. We interviewed 58 clients about their experiences shortly after the interview, a further 36 of these clients were re-interviewed about their cases three or four months after the interview to get a stronger sense of how their cases had developed. Two workshops were held with advisers and stakeholders to discuss the research and assist in the analysis of findings.

\section{Results: how multiple problems are managed}

The analysis in this study was able to focus on the specialities of the particular advisers who were interviewed, and also the specialties contained within the organisation. This enabled an exploration of the extent to which the adviser's expertise and/or the expertise available within their organisation, shaped the trajectory of client service delivery.

Because we had data on the specialties of the advisers we observed and of the organisation, more broadly we were able to look at whether a client approached an organisation that had a specialist in that type and also whether the:

- problems presenting to specialists that were within their specialism;

- problems presenting to specialists that were outside their specialism; and,

- problems presenting to generalists (who by definition did not have a specialism).

The first finding of note is that both generalists and specialists failed to probe beyond presenting problems and identify non-presenting problems, even when these might be

\footnotetext{
${ }^{32}$ A mixture of solicitors, Citizens Advice Bureaux (CABx), law centres/specialist advice agencies and local authority providers in three main areas of social welfare law where clusters were particularly likely to occur: housing, benefits and debt
} 
related to the presenting problem (e.g. a debt problem that was related to a welfare benefits problem) (Moorhead et al 2006: 51 et seq). However it was not possible to discern concrete differences between specialists and generalists in this regard: both missed latent problems.

Greater differences occurred in the way they managed problems that were identified that were outside the specialists' expertise. Both generalist advisers and specialists who are faced with problems outside their expertise were, as one would expect, less able or willing to deal fully with such problems than specialists faced. Some simply acknowledged the problems rather than providing any advice, a strategy which was more marked for specialists than generalists. Generalists were also more likely to advise clients to deal with the problem themselves whereas specialists were more likely to tell the client there was no action they could take (even though they did not have specialist knowledge of the problem type; a strategy which Anatomy of Access suggests was often implicated in poor quality). Similarly, generalists were much more likely than specialists faced with problems outside their expertise to signpost or signpost or refer clients to another source of advice (Moorhead et al 2006: 43): generalists did this for $28 \%$ of problems; specialists did this for $13 \%$ of problems they were not specialist in.

The difference in signposting/referral activity is intriguing. Why were generalists signposting/referring more often than specialists? One explanation is that for generalists, signposting was a more central part of their job. They were expected to identify problems, deal with those that were not complex, and signpost on those that required more detailed assistance. Specialists were in a different position: they saw their job as dealing with the problems they were expert in. When faced with something outside their expertise they might give some advice (a strategy which Anatomy of Access would suggest we ought to be worried about) or tell the client nothing could be done rather than refer the client on to someone who better understood the particular problem despite the contractual requirement under legal aid to signpost or refer clients on. ${ }^{33}$

\footnotetext{
33 The Specialist Quality Mark Standard states that, "Where a member of the Community Legal Service (CLS) or the Criminal Defence Service (CDS) cannot provide the particular service needed by
} 
Furthermore, generalists seemed most likely to advise that the client should deal with the problem themselves. Anatomy of Access showed the dangers of this (Moorhead and Sherr, 2003: 57-58) and the Clusters Study showed that the capacities of clients to deal with problems themselves was also significantly questioned by clients who often felt totally out of their depth (Moorhead et al 2006: 78-81). The specialists dealing with a problem outside their specialism more often indicated a willingness to help which did not commit to representation or negotiation on behalf of the client and also more often indicated no action was available. Again, there is an evidenced risk that advisers dealing with problems outside of their own specialism, misdiagnose them as ones for which there is no solution when in fact a solution does exist (Moorhead and Sherr, 2003: 57).

\section{Organisational expertise}

The Clusters Study also considered whether the expertise of the organisation had an impact on the way the client's problem manifested and was dealt with. For example, client choices and adviser strategies during interviews might both be influenced by the organisation within which an interview was taking place. A client might be more likely to raise problems outside an adviser's expertise where they know that the organisation deals with such problems. Furthermore, an adviser might be more likely to, or more confident in, dealing with problems that they know their colleagues deal with either because they are more sensitised to those (e.g. through intra-organisational training or the opportunity to discuss a wider range of problems with colleagues) or because they know they can refer the client on relatively easily. Alternatively, they may have a stronger incentive to identify and deal with problems where it helps their organisation fund more cases under contracts. The opposite is also possible. Suppliers who are operating beyond their capacity may have an incentive to pass cases on to other suppliers, even where they deal with those problems in-house. The advice strategy for generalists did not differ significantly depending on their institutional

the client, they must inform the client and direct them to an alternative service provider, where available.” LSC (2005), p. 32. 
context nor did that for specialists. ${ }^{34}$ The results suggest that adviser characteristics and roles are more important determinants of advice strategy than the organisation's capacities. The one area where this was not the case was signposting/referral behaviour: generalist advisers’ levels of signposting did not differ significantly depending on the organisational context but specialists did. ${ }^{35}$ Specialists were more likely to signpost or refer clients on to other advisers where their own organisation had the extra expertise. This is suggestive of a reluctance by specialists to refer/signpost clients outside of their own organisations. In this sense specialisation may interact with organisational context to make consumer detriment more likely.

\section{Conclusions and implications}

The results show that, for legal aid practitioners, the levels of competence of nonspecialists are worryingly low. In absolute terms, the levels of incompetence shown in the Anatomy of Access and Quality and Access studies genuinely question the extent to which a professional qualification acts as a general warrant of competence. Specialists on the other hand show higher, but not always satisfactory, levels of competence. As Quality and Access indicates, however, the imposition of compulsory specialisation in legal aid has also had a significant detrimental impact on access to justice. Suppliers of specialist services are necessarily fewer and less geographically dispersed than more generalist providers. The Clusters study suggests that there is some, albeit modest, evidence that cognitive narrowness is a problem rightly associated with specialisation.

From this it can be seen that specialisation shows both functionalism and control to be genuinely in play. Importantly for theories which like to portray professions as fundamentally controlling or functional, the data recorded here suggests that functionalism and control are mutually constitutive of each other. Specialisation does indeed improve quality, but this improvement is engendered at a cost to consumers (here in terms of reduced access to justice, rather than increased costs but in freer markets than legal aid one might predict that prices would rise). It is inevitable, then,

\footnotetext{
${ }^{34}$ Moorhead et al 2006:47

${ }^{35}$ Ibid. 49
} 
that both functionalism and control predict the profession's behaviour simultaneously. As a result, those regulating specialisation (here the LSC, but the point applies to any professional regulator) are engaged in a process of a managed paradox.

How are the trade-offs engendered by specialisation to be managed? The diminution in access cannot easily be compared with the increase in quality: the two issues are incommensurate. Nor do the two dominant theories of professions assist: market control theories predict specialisation will be structured to benefit the profession; structural functionalists, that it will be benefit the public. Specialisation benefits specialists and their clients and harms the generalists and their clients, or (more accurately) highlights the harm caused to the clients who cannot access specialist advice (who either get poorer quality advice or no access at all).

This suggests that closer attention should be paid to how the balance is struck, who strikes it and what mechanisms can be used to diminish the antithesis rather than trying to prove that specialisation (or professionalism) is inherently functional or inherently controlling. A contrast between the LSC and the Solicitors' Regulation Authority, the regulatory arm of the solicitor's professional body - the Law Society, is illuminating. The LSC, for example, has clearly struck the balance in favour of compulsory specialisation. They have done so in consultation with the profession (which had a view somewhat hostile to the LSCs position) and with considerable power as a monopsonic purchaser. Furthermore, they have sought to diminish the importance of the trade-off between access and quality by making telephone advice a vehicle for diminishing the access problems and moved to solve some of the cognitive narrowness problems by seeking to bring specialists together in Community Legal Advice Centres or Networks (CLACs and CLANs) so that as many specialisations operate under one roof, or within one network, as possible. Whether these reforms will genuinely resolve the dilemmas posed by specialisation or are mere window dressing remains to be seen.

The solicitor profession's approach stands in contrast. Specialisation is not specifically a regulatory tool which licenses practitioners of certified competence to practice in a particular area but as a marketing tools to promote specialist work. In this way, the Law Society (and latterly the Solicitors Regulation Authority) have tended towards accepting the idea of omni-competence: that general professional 
qualification is sufficient to guarantee competence across the range of legal services whilst seeking to accommodate the claims of specialist (and their desire to accredit and advertise themselves as such) without granting them exclusive control of particular types of work. This response is founded on two concerns. The first is to protect the validity of the general professional qualification as a general warrant of competence. This is part of the profession's fundamental claim to legitimacy. The second is a wariness of delivering control over particular markets to specialists (see, for example SRA 2007:4).

The profession, in accrediting specialists, is thus forced into accepting the benefits of specialisation whilst also seeking to protect the interests of non-specialists by not according specialists' market control. This it usually does by ensuring specialisation is voluntary and also open to all those who demonstrate basic levels of experience, rather than higher, levels of competence (SRA 2007: 4). There are international parallels. Kahn and Kahn describe how in the 1970s, the ABA resisted the development of a specialist criminal accreditation scheme which might test competence or look to minimum levels of regular experience in a criminal practice in favour of a scheme which aimed at those wishing to claim the ability to say they were qualified in criminal law (Kahn and Kahn 1977: 268 et seq). Specialists are thus not generally granted a monopoly beyond that afforded to the profession generally. The ABA's concerns were typical and are echoed in more current debates about specialisation. They wished to prevent the creation of, "a small coterie of high-priced criminal lawyers by promulgating nearly unattainable standards” (ibid 269); to limit costs to clients; to protect the solo general practitioner; and to protect access to justice in rural areas (ibid 289). And yet there is something very strange in a profession, which by virtue of its high entry standards and protracted period of training, claims a general warrant of competence (and often monopoly) over legal work, and yet recognises specialist accreditation schemes which are neither granted any form of monopoly nor have higher standards demanded of them than mere competence.

The latter concern emphasises the paradox of specialisation because it requires professions to accept the 'market control' thesis - the idea that specialisation acts to the detriment of consumers because it inhibits competition - whilst claiming that same protection from competition for the profession as a whole. The position 
becomes particularly paradoxical if one is to assume that that the results outlined above in relation to legal aid practitioners holds generally. If generalist's work shows significant levels of incompetence in absolute terms and relative to specialists, the profession is denying particular market protection to those that are competent whilst it protects the incompetent when faced with competitive threats from outside the profession. At first blush, the position is both incoherent and contrary to the public interest.

It might however be possible to justify their approach on two bases. One would be that the consumer detriment that would be suffered by increasing specialisation in terms of reduced access and increased costs may be more serious than the improvements in quality that would result from restricting all work to specialists. Accreditation of specialists on a voluntary, rather than compulsory basis, would allow the market to decide whether specialists should be preferred to generalists. There are a number of imponderables in this argument: particularly the unknown extent to which consumers recognise and act on the benefits of specialisation. There is of course impediment to consumers doing this: in particular a significant lack of information by which they can gauge the relative quality of providers. In any event, the 'let the market decide' strategy is further undermined by the second limb of professional policy on this issue: the idea that standards for specialist accreditation schemes should be modest. This is harder to justify under a voluntary scheme as it dilutes the utility of the concept of specialisation. Consumers are provided with an opportunity to choose between (presumably cheaper and/or local) generalists and (more expensive and/or geographically distant) specialists who in fact have reached a standard not dissimilar to that which all generalists should be able to achieve. The result is that a weak and voluntary standard diminishes the extent to which consumers can make a genuine choice between generalists and 'real' specialists.

Interestingly, we can see also here how the specialisation as fragmentation problem plays out. The fragmentation thesis is that specialisation weakens the profession's ability to speak as one on regulatory issues (Seron op.cit.: 593) and yet the policy on specialisation is very difficult to explain as anything other than an attempt by the profession to speak and act as one: protecting the interests of specialists and generalists in a way which maintains a degree of unity over and above the public 
interest. For me this suggests a weakness in the idea that we should see the fragmentation thesis as threatening the profession: a profession which more explicitly defined and managed its differences might more strongly protect the public interest and better match the way law is, or ought to be, practised on the ground. After all, the medical profession has a much stronger and better developed sense of specialisation which has not damaged its professional standing. Fragmentation is a sociological distraction when a much more fundamental issue about professions is in play: their core claim to competence.

Would an approach which better formalised specialisation fatally undermine the profession's legitimacy? That must be a risk, but it would be a risk borne out of the profession's inability to render its general warrant of competence meaningful. The general qualification might become a staging post on the way to specialist practice (which would suggest training costs would increase not decrease as a result of specialisation) or it might whither with lawyers qualifying more directly as specialists (where training costs, and so prices for clients, might be expected to be lower). There are other risks in such developments of course: the cognitive narrowing caused by specialisation is a real risk, as has been shown above, but the evidence so far suggests it is a modest risk and generalists only do 'better' in holistic terms if they have specialists to refer to. Specialist accreditation schemes do risk building in inflexibilities as markets and new areas of law develop. This suggests that voluntary schemes are likely to be more appropriate than compulsory schemes, but that the professions (or other regulators) have to do more to support and define genuine specialisation as a core proxy for quality. Their claim exclusive competence, and so their legitimacy, depends upon it.

-end-

\section{Bibliography}

1. Abel, R.L. (1989) American Lawyers . New York: Oxford University Press

2. Abel, Rick L (1997) Lawyers: A Critical Reader (New Press, New York) 
3. Bottazzi, Lura, Marco Da Rin and Thomas Hellmann (2004) Active Financial Intermediation: Evidence on the Role of the Organizational Specialization and Human Capital ECGI Working Paper 49/2004.

4. Cain, Mauren (1979) The General Practice Lawyer and the Client: Towards a Radical Conception International Journal of the Sociology of Law 331

5. Estevadeordal, Antoni and Christian Volpe Martincus (2006) Specialization and Diverging Manufacturing Structures: The Aftermath of Trade Policy Reforms in Developing Countries Centro Studi Luca d'Agliano Development Studies Working Paper No. 220.

6. Feinberg, Robert M.(1994) Paralegals and Associate Lawyers: Substitutability Within the Law Firm, 1977-87 The Review of Economics and Statistics, Vol. 76, No. 2 (May, 1994), pp. 367-372.

7. Freidson, Eliot (2001) Professionalism: The Third Logic (Cambridge: Polity)

8. Galanter, Mark (1990) Why the Big Get Bigger: The Promotion-to-Partner Tournament and the Growth of Large Law Firms, 76 Virginia Law Review 747

9. Garicano, Luis and Thomas N. Hubbard (2003) Firms' Boundaries and the Division of Labor: Empirical Strategies 1(2-1) Journal of the European Economic Association 495-502

10. Garicano, Luis and Thomas N. Hubbard (2004) Hierarchies, Specialization and the Utilisation of Knowledge: Theory and Evidence from the Legal Services Industry, Working Paper 10432 (Cambridge: National Bureau of Economic Research).

11. Genn, Hazel and Yvette Genn (1989), The Effectiveness of Representation at Tribunals

12. Hadfield, Gillian K (1999) The Price of Law: How Markets for Lawyers Distorts the Justice System 98 Michigan Law Review 953 
13. Heinz John P., Robert L Nelson, Rebecca L. Sandefur and Edward O. Laumann (2005) Urban Lawyers: The New Social Structure of the Bar (Chicago and London; University of Chicago Press)

14. Heinz, J.P. and Laumann, E.O. (1982) Chicago Lawyers: The Social Structure of the Bar . Chicago: American Bar Foundation .

15. Heinz, J.P., Nelson, R.L., Laumann, E.O., and Michelson, E. (1998) The changing character of lawyers' work: Chicago in 1975 and 1995 , Law \& Society Review (32) 751-755.

16. Kahn, Michael H. and Lisa Davidson Kahn (1977) Specialization in Criminal Law 41 Law and Contemporary Problems 252-292

17. Kritzer, Herbert M (1999) The Professions Are Dead, Long Live the Professions: Legal Practice in a Postprofessional World, Law \& Society Review Vol. 33, No. 3, pp. 713-59

18. Kritzer, HM (1999) Legal Advocacy (The University of Michigan Press, Michigan)

19. Kronman, A (1993) The Lost Lawyer - Failing Ideals of the Legal Profession (Belknap Press: Cambridge and London)

20. Law, Marc T. and Sukkoo Kim (2005) Specialization and Regulation: The Rise of Professionals and the Emergence of Occupational Licensing Regulation, 65 The Journal of Economic History 723-756

21. Laumann, Edward O and John P. Heinz (1977) Specialization and Prestige in the Legal Profession American Bar Foundation Research Journal 155-216

22. Moorhead Richard and Richard Harding (2004) Quality and Access: Specialist and tolerance work under civil contracts (Norwich: Stationery Office)

23. Moorhead Richard and Avrom Sherr (2003) An Anatomy of Access:

Evaluating Entry, Initial Advice and Signposting using model clients (London: LSRC) 
24. Moorhead Richard, Margaret Robinson and Matrix Research and Consultancy (2006) A trouble shared - legal problems clusters in solicitors' and advice agencies, (London: Department for Constitutional Affairs)

25. Moorhead, Richard (2004) Legal aid and the decline of private practice: blue murder or toxic job?' 11 (3) International Journal of the Legal Profession 159

26. Moorhead, Richard, Avrom Sherr and Alan Paterson, Contesting Professionalism: Legal Aid and Nonlawyers in England and Wales, (2003) 37 Law \& Society Review 765-808

27. Moorhead, Richard, Avrom Sherr, Lisa Webley, Sarah Rogers, Lorraine Sherr, Alan Paterson and Simon Domberger (2001) Quality and Cost: Final Report on the Contracting of Civil, Non-Family Advice and Assistance Pilot (Norwich: Stationery Office)

28. Moorhead, Richard Avrom Sherr and Alan Paterson (1994) Judging on results? Outcome measures: quality, strategy and the search for objectivity 1 (2) International Journal of the Legal Profession 191

29. Nelson, Robert L (1988) Partners with Power: The Social Transformation of the Large Law Firm (University of California Press)

30. Pleasence, Pascoe and Alexy Buck, Nigel Balmer, Aoife O’Grady, Hazel Genn, Marisol Smith (2004) Causes of Action: Civil Law and Social Justice (Stationery Office: Norwich)

31. Gordon, Robert (2000) Why Can't Lawyers Just Be Hired Guns? in DL Rhode (ed) Ethics in Practice: Lawyers' Roles , Responsibilities, and Regulation (OUP, Oxford and New York 2000)

32. Sander, Richard H and Douglass Williams (1989) A Little Theorizing about the Big Law Firm: Galanter, Palay, and the Economics of Growth 17 (3) Law \& Social Inquiry 391

33. RJ Gilson (1992) How Many Lawyers Does it Take to Change an Economy? 17 Law and Social Enquiry 635 
34. RJ Gilson (1984) Value Creation by Business Lawyers: Legal Skills and Asset Pricing 94 Yale Law Journal 239

35. Rostain, Tanina (2004) Professional Power: Lawyers and the Constitution of Professional Authority in A. Sarat (ed.) The Blackwell Companion to Law and Society (Oxford: Blackwell)

36. Schõn, DAThe Reflective Practitioner: How Professionals Think in Action ((Basic Books, New York) (London : Temple Smith)

37. Seron, Carroll (2007) The Status of Legal Professionalism at the Close of the Twentieth Century: Chicago Lawyers and Urban Lawyers 32/2 Law and Social Inquiry 581-607

38. Shiner and Newburn, (1995) Policy Studies Institute, Entry into the Legal Professions: the Law Student Cohort Study Year 3, (London: Law Society)

39. Sommerlad, H (2001) I've lost the plot': An Everyday Story of the 'Political' Legal Aid Lawyer, 28(3) Journal of Law \& Society 335-360

40. Sommerlad, H and D Wall (1999) Legally Aided Clients and Their Solicitors: qualitative perspectives on quality and legal aid (London: Law Society)

41. Sommerlad, H (1995) Managerialism, and the legal profession: a new professional paradigm, 2 International Journal of the Legal Profession 159

42. Stefancic, Jean and Richard Delgado (2005) How Lawyers Lose Their Way: A Profession Fails Its Creative Minds University of Pittsburgh School of Law Working Paper Series, Year 2005 Paper 29 
Published by Cardiff Law School, Cardiff University Museum Avenue, Cardiff CF10 3AX, Wales, United Kingdom

www.law.cf.ac.uk/researchpapers/5.html

(C) Richard Moorhead 2008 